\title{
Cortical Regions for Judgments of Emotions and Personality Traits from Point-light Walkers
}

\author{
Andrea S. Heberlein*, Ralph Adolphs, Daniel Tranel, \\ and Hanna Damasio
}

\begin{abstract}
- Humans are able to use nonverbal behavior to make fast, reliable judgments of both emotional states and personality traits. Whereas a sizeable body of research has identified neural structures critical for emotion recognition, the neural substrates of personality trait attribution have not been explored in detail. In the present study, we investigated the neural systems involved in emotion and personality trait judgments. We used a type of visual stimulus that is known to convey both emotion and personality information, namely, point-light walkers. We compared the emotion and personality trait judgments made by subjects with brain damage to those made by neurologically normal subjects and then conducted a lesion overlap analysis to identify neural regions
\end{abstract}

\section{INTRODUCTION}

People are exceedingly adept at using subtle visual cues to guide their social judgments of others. Even impoverished stimuli, such as static pictures of posed facial expressions, or very brief "thin slices" of whole-body movements (Ambady \& Rosenthal, 1992), elicit reliable judgments of emotion, personality, or both from human raters. Both emotion recognition (e.g., coming to the knowledge that Person $\mathrm{X}$ feels sad) and trait attribution (e.g., coming to believe that Person Y is trustworthy) depend on serial processes: (1) perception of the stimuli, (2) relating the observed behavior to prior knowledge and expectancies about how the behavior relates to various psychological states or traits, and thus (3) inferring the state or trait (Adolphs, 2002; Macrae \& Bodenhausen, 2000; Gilbert, 1998). Evidence suggests that substantial components of these processes happen rapidly and relatively automatically, although more effortful, conscious components certainly play a significant role (e.g., the consideration of situational constraints in trait attribution; (Greenwald \& Banaji, 1995; Fiske, 1993). In our study, we asked subjects to make judgments

\section{University of Iowa}

*Current affiliations: Center for Cognitive Neuroscience University of Pennsylvania and Childrens Hospital of Philadelphia. critical for these two tasks. Impairments on the two tasks dissociated: Some subjects were impaired at emotion recognition, but judged personality normally; other subjects were impaired on the personality task, but normal at emotion recognition. Moreover, these dissociations in performance were associated with damage to specific neural regions: Right somatosensory cortices were a primary focus of lesion overlap in subjects impaired on the emotion task, whereas left frontal opercular cortices were a primary focus of lesion overlap in subjects impaired on the personality task. These findings suggest that attributions of emotional states and personality traits are accomplished by partially dissociable neural systems.

about emotional states and about personality traits, from human body movement stimuli. We investigated the neural substrates of these two types of social judgments by examining which regions of brain damage were associated with deficits in task performance in each case.

Studies of the processes by which people infer emotional states commonly use the word recognition. In contrast, the processes by which people infer personality traits are commonly called attribution, which implies a greater role for existing concepts and expectancies on the part of the attributer (it is a matter of debate whether personality traits, defined as enduring characteristics that are predictive of behavior, in fact exist at all, e.g., Mischel \& Shoda, 1995; nonetheless, these are judgments that people make readily). For the sake of simplicity, we will use the term judgment for both processes.

\section{Point-Light Walkers and Social Cognition}

The ability to predict behavior from inferred mental states and traits confers significant advantages on an individual living in a social context. A major contribution to this ability derives from the capacity to make quick and accurate categorizations of the feelings and action tendencies of other individuals based on their nonverbal behavior. Often, one can perceive patterns of body 
motion posture, gait, and trajectory cues before other visual cues such as facial expression are available. Thus, it is not surprising that people can extract a considerable amount of information from body movement, even given fairly impoverished cues. An experimentally useful method of depicting body movements was discovered by Johansson (1973), who attached small "point-lights" to the major joints of actors and filmed them walking or running in a dark room. In static form, they appear as a random series of dots; however, the moving lights are immediately recognizable as human motion (often called "biological motion"). Johansson's point-light technique eliminates most morphological cues while preserving the natural relative movements of body parts.

Using point-light biological motion stimuli, researchers have shown that people recognize not just types of locomotory movement from point-light stimuli, but also gender (Kozlowski \& Cutting, 1977), identity of friends (Cutting \& Kozlowski, 1977), traits such as vulnerability (Gunns, Johnston, \& Hudson, 2002), and emotional states (Makeig, 2001; Pollick, Paterson, Bruderlin, \& Sanford, 2001; Dittrich, Troscianko, Lea, \& Morgan, 1996). To portray emotional states, Dittrich et al. (1996) used whole-body point-light displays of people dancing, and Makeig (2001) constructed point-light displays from whole bodies filmed in various types of movements. In contrast, Pollick et al. (2001) recently showed that people can recognize affective states even from point-light depictions of arms engaging in simple actions such as drinking and knocking. People's ability to derive socially relevant information from such impoverished cues is striking: Body movement is clearly a useful source of information about others' states and traits.

There have been several recent studies examining the neural substrates of biological motion perception (see below). However, despite a recent surge of interest in the neurobiology of emotion and social perception, few neurobiological studies have focused on biological motion cues that convey emotion or personality information.

\section{Neural Structures Associated with Emotion Recognition and Personality Trait Recognition}

Several cortical and subcortical structures are critical for the recognition of emotional states in others. The amygdalar nuclei have been implicated in the recognition of facial expressions of emotion, most often fear, by both lesion (Adolphs et al., 1999; Sprengelmeyer et al., 1999; Calder, Young, Perrett, Hodges, \& Etcoff, 1996; Adolphs, Tranel, Damasio, \& Damasio, 1995; Young et al., 1995) and functional imaging studies (Whalen et al., 1998; Breiter et al., 1996; Morris et al., 1996). Orbitofrontal cortices have also been implicated in facial emotion recognition (Kawasaki et al., 2001; Vuilleumier, Armony, Driver, \& Dolan, 2001; Marinkovic, Trebon,
Chauvel, \& Halgren, 2000; Dolan et al., 1996; Hornak, Rolls, \& Wade, 1996). In contrast, insular cortices have been implicated in the recognition specifically of disgust (Calder, Keane, Manes, Antoun, \& Young, 2000; Phillips et al., 1998; Sprengelmeyer, Rausch, Eysel, \& Przuntek, 1998). Damage to cortices in the right hemisphere has been shown by several authors to result in impairments recognizing emotional expressions (Borod et al., 1998; Bowers, Bauer, Coslett, \& Heilman, 1985; Benowitz et al., 1983), and recent evidence from both functional neuroimaging (Winston, O’Doherty, \& Dolan, 2003) and from lesion overlap studies (Adolphs, Damasio, \& Tranel, 2002; Adolphs, Damasio, Tranel, Cooper, \& Damasio, 2000) suggests that right-hemisphere somatosensory cortices are especially important for emotion recognition. These latter two studies also found deficits consequent to frontal operculum damage in emotion recognition from faces (Adolphs et al., 2000) and from prosody (Adolphs et al., 2002); the frontal operculum has also been implicated in facial emotion recognition in a functional imaging study (Kesler-West et al., 2001).

The connection between damage to the somatosensory cortex or frontal opercular cortex and impaired emotion recognition suggests a model of emotion recognition in which internally modeling the observed action plays a significant role. A simulation mechanism involving the frontal operculum has been proposed by other authors to underlie not only imitation but also social cognitive behaviors such as inference of intention (Blakemore \& Decety, 2001; Gallese \& Goldman, 1998). Adolphs et al. (2000, 2002) suggested that such simulation processes may also underlie emotion recognition and may involve right-hemisphere somatosensory cortices in addition to frontal operculum.

In contrast to studies of the recognition of emotional states, few studies have examined the neural substrates underlying attribution of personality traits. Judgments of trustworthiness based on photographs of faces have been shown by both lesion (Adolphs, Tranel, \& Damasio, 1998) and functional imaging (Winston, Strange, O'Doherty, \& Dolan, 2002) studies to involve the amygdala. However, it is not known how subjects with damage to other areas fare on this type of task, or whether the judgment of other personality traits relies on the amygdala or (not incompatibly) relies on simulation-related cortices, such as premotor and somatosensory areas.

Recent imaging studies have found amygdala activation correlating with the engagement of negative racial stereotypes (i.e., series of linked representations of social knowledge; Hart et al., 2000; Phelps et al., 2000) and ventromedial prefrontal cortices may be implicated in implicit gender stereotyping (Milne \& Grafman, 2001). However, the social judgments involved in these studies addressed gender and race stereotypes and not specific personality traits such as extraversion or warmth, and 
thus it is difficult to apply these findings to the attribution of such traits.

Several studies have examined PET or fMRI activation to biological motion stimuli, implicating cortices along the posterior superior temporal sulcus (STS) in the perception of such stimuli (Grossman \& Blake, 2002; Servos, Osu, Santi, \& Kawato, 2002; Grezes et al., 2001; Vaina, Solomon, Chowdhury, Sinha, \& Belliveau, 2001; Allison, Puce, \& McCarthy, 2000; Grossman et al., 2000). Of all of the studies that examined neural activations in humans viewing point-light displays of biological motion, only Bonda, Petrides, Ostry, and Evans (1996) used stimuli that were intended to convey emotional or social meaning. These authors contrasted the patterns of PET activation observed when subjects watched expressive whole-body dancing movements with those observed when subjects watched an example of goal-directed movement, namely, a hand picking up a glass and drinking. During viewing of expressive body movements, they observed more activity in right STS and adjacent temporal cortex, as well as in the amygdala.

In the present study, we showed point-light stimuli to 37 subjects with brain damage, as well as age-, gender-, and education-matched neurologically normal control subjects. All subjects completed emotion and personality judgment tasks, as well as a control task of simple movement labeling. We conducted two kinds of analyses: (1) a lesion overlap analysis of emotion and of personality trait judgments, using the entire sample of subjects and (2) an analysis specifically of those subjects with damage in right somatosensory cortices. These analyses permitted a detailed investigation of the neural substrates necessary for emotion and personality judgments, and of the possible reliance of these processes on right somatosensory cortex, as implied by earlier studies of face- and prosody-based emotion tasks. Because another region, the left frontal operculum, was implicated in the personality task based on the first analysis, we also specifically compared subjects with left frontal opercular damage to normal controls on this task.

\section{RESULTS}

Across the 37 brain-damaged subjects we tested, there was a weak correlation between scores on the two social judgment tasks (Pearson's $r=.45$ ). However, it is not this overall correlation that is of interest, but rather the deviations from it. Whereas there are 5 subjects who were impaired on both tasks, we found a double dissociation across subjects: 7 were impaired on the emotion task but not the personality task, and 4 were impaired on the personality task but not on the emotion task. We first discuss cortical regions associated with each social judgment deficit, and then explore the dissociation with further lesion overlap analyses.

\section{Emotion Judgments}

Thirteen of the total of 37 brain-damaged subjects we tested were impaired at judging emotion from pointlight walkers ( $>2 S D$ s below matched normal controls [NCs]; this includes the 5 impaired on both tasks and the 7 impaired only on the emotion task, as well as 1 who was impaired on the emotion task but gave an invalid performance on the personality task; see Methods). We constructed a lesion overlap image by tracing the lesions of all impaired subjects onto a common reference brain (Figure 1) (Damasio, 2000). This revealed an area of maximal overlap in right somatosensory cortices. As can also be seen from this figure, damage to multiple parts of the brain could result in impairments in emotion recognition from point-light walkers, consistent with a distributed system for emotion recognition with multiple participating components. However, the regions in which lesions were most consistently associated with impairments in emotion judgment were the right somatosensory cortices (see also Table 1). To control for inhomogeneous sampling of lesion locations throughout the brain, we also calculated lesion overlaps that were normalized relative to the total lesion sampling densities across the brain (see Methods for details, and Figure 2 for the total distribution of lesion sampling density). This normalized calculation also showed a maximal lesion overlap in right somatosensory cortices, confirming that this lesion overlap could not be attributed solely to our sampling of lesions.

There were no clear differences in the regions of lesion overlap associated with impaired judgment of specific individual emotions.

\section{Personality Judgments}

A different set of subjects, 9 in total, was impaired at judging personality traits from point-light walkers $(>2$ $S D$ s below NC mean). Seven of these nine subjects had damage on the left side, with a focus of maximal lesion overlap in the left premotor areas, more specifically in the posterior sector of the frontal operculum (Figure 3; see also Table 1). We again recalculated these lesion overlaps normalized relative to sampling densities across the brain, and confirmed that the area of maximal lesion overlap in left frontal opercular cortices did not result from sampling bias.

There were no clear differences in the regions of lesion overlap associated with impaired judgment of specific individual personality traits.

\section{Relationship between Emotion Recognition and Personality Trait Recognition}

A comparison of Figures 1 and 3 shows that impairments on each task are associated with disproportionate 
Figure 1. Lesions that impair recognition of emotion. Shown are the overlaps of lesions (color scale) from subjects who were impaired at emotion recognition from point-light walkers ( $>2 S D$ s below NC mean). The greatest overlap was in right somatosensory regions. Normalization for overall lesion sampling density revealed a similar pattern (not shown). Note that the right sides of coronal images correspond to the left side of the brain.
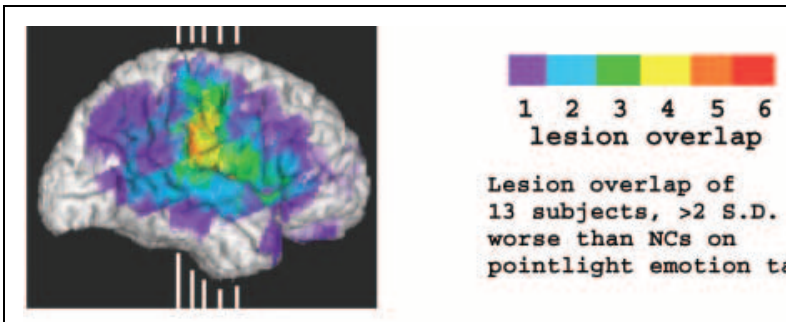

Lesion overlap of

13 subjects, >2 S.D.

worse than NCs on

pointlight emotion task
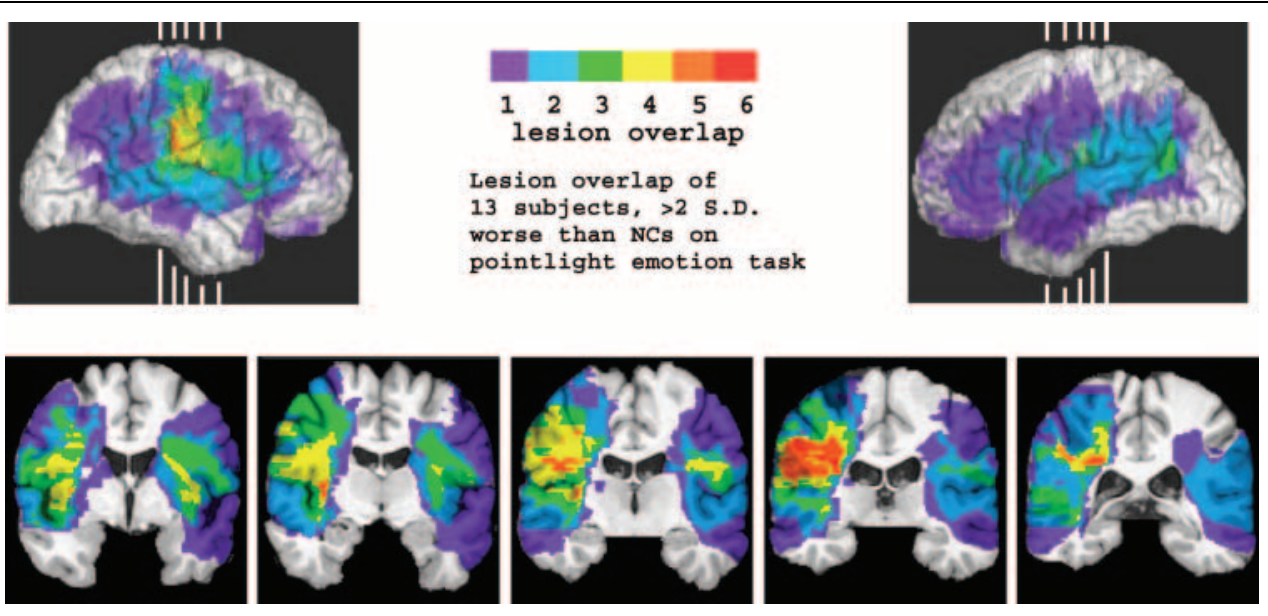

damage to different brain regions. To explicitly address the question of which cortical regions are more critical for one task than the other, we compared the lesion overlaps of subjects who performed relatively worse on one task than on the other (see Methods for details). Figure 4 (top) shows the lesion overlap of eight subjects who were more impaired on the emotion task than on the personality task. The region of maximal overlap includes right somatosensory cortices, particularly postcentral gyrus and insula. The bottom half of Figure 4 shows the results for seven subjects who performed worse on the personality task than on the emotion task. These results, like those for all subjects impaired on the personality task (Figure 3), show a maximal overlap of lesions in left prefrontal cortices.
Figure 2. Total lesion sampling density. Shown are the overlaps of the lesions from all 37 subjects who participated in the study.

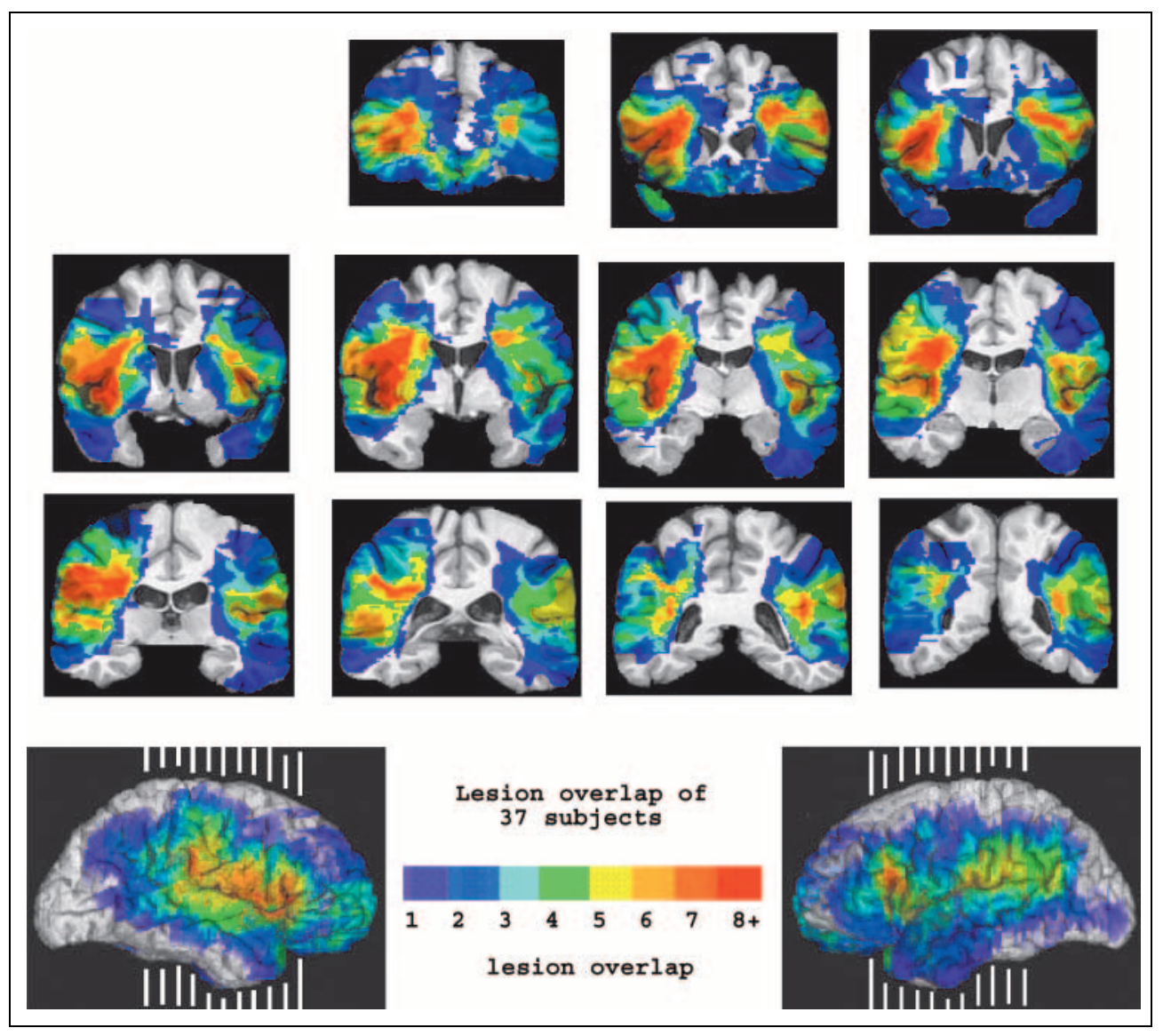




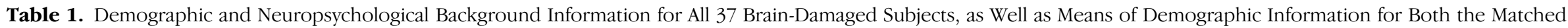
and Reference Normal Control (NC) Groups

\begin{tabular}{|c|c|c|c|c|c|c|c|c|c|c|c|c|c|c|c|c|}
\hline \multirow[b]{2}{*}{$\begin{array}{c}\text { Subject } \\
\text { No. }\end{array}$} & \multirow[b]{2}{*}{$\begin{array}{c}\text { Lesion } \\
\text { Location }\end{array}$} & \multirow[b]{2}{*}{$\operatorname{sex}$} & \multirow[b]{2}{*}{ Hand } & \multirow[b]{2}{*}{$\begin{array}{l}\text { Education } \\
\text { (years) }\end{array}$} & \multirow[b]{2}{*}{ Age } & \multirow{2}{*}{$\begin{array}{l}\text { Time since } \\
\text { Lesion } \\
\text { Acquired }\end{array}$} & \multicolumn{4}{|c|}{ WAIS Subtests } & \multirow[b]{2}{*}{$\begin{array}{c}\text { Faces } \\
\text { (Adj) }\end{array}$} & \multirow[b]{2}{*}{$\begin{array}{l}\text { Lines } \\
\text { (Adj) }\end{array}$} & \multirow[b]{2}{*}{$\begin{array}{l}\text { BVRT } \\
\text { CORR }\end{array}$} & \multirow[b]{2}{*}{$\begin{array}{c}B V R T \\
\text { ERROR }\end{array}$} & \multirow[b]{2}{*}{$\begin{array}{l}\text { Depression } \\
\text { Index }\end{array}$} & \multirow[b]{2}{*}{$\begin{array}{l}\text { Aphasia } \\
\text { Index }\end{array}$} \\
\hline & & & & & & & Similarities & Information & Comprehension & $\begin{array}{c}\text { Matrix } \\
\text { Reasoning }\end{array}$ & & & & & & \\
\hline \multicolumn{17}{|c|}{ Subjects impaired on emotion task (>2 SDs below normal control mean) } \\
\hline 0650GR & RSS & M & 90 & 10 & 58.75 & 15.5 & 9 & 6 & 9 & 7 & 45 & 26 & 9 & 2 & 0 & 0 \\
\hline $0744 \mathrm{ES}$ & RSS, STS & M & 100 & 8 & 83.6 & 15.5 & 14 & 16 & 13 & 11 & 43 & 30 & 7 & 4 & 0 & 0 \\
\hline $1106 \mathrm{MB}$ & bi OFC, RSS & M & 100 & 12 & 56.75 & 13.5 & 13 & 9 & 10 & 8 & 41 & 20 & 4 & 10 & 0 & 0 \\
\hline 2107WM & RSS & M & 100 & 12 & 60 & 4.5 & 11 & 11 & 11 & 9 & 42 & 22 & 5 & 8 & 0 & 0 \\
\hline 1981RG & $\mathrm{R}$ parietal & M & 100 & 16 & 68.5 & 6.75 & 13 & 12 & 12 & 13 & 50 & 29 & 8 & 3 & 0 & 0 \\
\hline $1637 \mathrm{CW}$ & RSTS (crossed) & $\mathrm{F}$ & 90 & 12 & 60.75 & 9 & 9 & 10 & 8 & $\mathrm{NA}$ & 43 & 26 & 7 & 5 & 0 & 1-crossed \\
\hline 1076GS & L PFC & M & 100 & 18 & 77.25 & 13.5 & $\mathrm{NA}$ & $\mathrm{NA}$ & $\mathrm{NA}$ & 12 & 44 & 25 & 5 & 7 & 0 & 3 \\
\hline 1366GG & L STS & M & 100 & 15 & 73.6 & 12.5 & 14 & 13 & $\mathrm{NA}$ & $\mathrm{NA}$ & 51 & 25 & 6 & 7 & 0 & 1 \\
\hline \multicolumn{17}{|c|}{ Subjects impaired on personality task ( $>2$ SDs below normal control mean) } \\
\hline $1760 \mathrm{KS}$ & LFO & M & 100 & 12 & 50.25 & 11 & $\mathrm{NA}$ & $\mathrm{NA}$ & $\mathrm{NA}$ & 7 & 45 & 22 & 5 & 7 & 0 & 3 \\
\hline $1772 \mathrm{ST}$ & LFO & $\mathrm{F}$ & 100 & 12 & 75.75 & 8.5 & 13 & 8 & 12 & 10 & 47 & 26 & 6 & 9 & 2 & 0 \\
\hline $1783 \mathrm{AW}$ & LFO & $\mathrm{M}$ & 100 & 16 & 76.5 & 9 & 10 & 13 & 10 & 11 & 41 & 30 & 7 & 6 & 0 & 0 \\
\hline $1033 \mathrm{AN}$ & L STS & $\mathrm{M}$ & 100 & 8 & 37.5 & 14.75 & 5 & 5 & 6 & 14 & 43 & 25 & 10 & 0 & 0 & 0 \\
\hline \multicolumn{17}{|c|}{ Subjects impaired on both tasks (>2 SDs below normal control mean) } \\
\hline 0770PK & bi OFC & $\mathrm{F}$ & 100 & 16 & 58.75 & 15.25 & 12 & 16 & 12 & 13 & 34 & 21 & 9 & 1 & 0 & 0 \\
\hline 1726RO & LFO & M & 100 & 12 & 66 & 10.5 & 6 & 8 & 4 & 9 & 42 & 29 & 6 & 6 & NA & 2 \\
\hline 1978JB & LFO & $\mathrm{F}$ & 100 & 12 & 55 & 5.5 & 6 & 10 & 5 & 12 & 47 & 22 & 6 & 5 & 0 & 3 \\
\hline $2394 \mathrm{EH}$ & L STS & $\mathrm{M}$ & -50 & 16 & 48 & 2.5 & $\mathrm{NA}$ & $\mathrm{NA}$ & $\mathrm{NA}$ & 12 & 45 & 27 & 8 & 3 & 0 & 3 \\
\hline $2126 \mathrm{JC}$ & RSS & F & 100 & 14 & 56.25 & 10.25 & 15 & 14 & 10 & 10 & 40 & 21 & 5 & 8 & 0 & 0 \\
\hline \multicolumn{17}{|c|}{ Subjects who performed normally on both tasks (within 2 SDs of normal control mean) } \\
\hline $1561 \mathrm{RB}$ & R PFC & M & 60 & 16 & 60.25 & 10.5 & 15 & 13 & 16 & 13 & 43 & 29 & 8 & 4 & 0 & 0 \\
\hline $1656 \mathrm{GG}$ & $\mathrm{R}$ insula & M & 100 & 12 & 57.75 & 8.5 & 10 & 10 & $\mathrm{NA}$ & 11 & 43 & 25 & 7 & 4 & 2 & 0 \\
\hline 1969CC & $\mathrm{RFO}$, insula & M & 100 & 12 & 60.25 & 6.25 & 10 & 12 & 12 & 8 & 44 & 29 & 5 & 9 & 1 & 0 \\
\hline 0747RH & RSS, STS & $\mathrm{M}$ & 100 & 14 & 51.75 & 10 & 9 & 15 & 12 & 10 & 41 & 23 & 9 & 1 & 0 & 0 \\
\hline
\end{tabular}




\begin{tabular}{|c|c|c|c|c|c|c|c|c|c|c|c|c|c|c|c|c|}
\hline \multirow[b]{2}{*}{$\begin{array}{c}\text { Subject } \\
\text { No. }\end{array}$} & \multirow[b]{2}{*}{$\begin{array}{c}\text { Lesion } \\
\text { Location }\end{array}$} & \multirow[b]{2}{*}{ Sex } & \multirow[b]{2}{*}{ Hand } & \multirow[b]{2}{*}{$\begin{array}{c}\text { Education } \\
\text { (years) }\end{array}$} & \multirow[b]{2}{*}{ Age } & \multirow{2}{*}{$\begin{array}{l}\text { Time since } \\
\text { Lesion } \\
\text { Acquired }\end{array}$} & \multicolumn{4}{|c|}{ WAIS Subtests } & \multirow[b]{2}{*}{$\begin{array}{l}\text { Faces } \\
\text { (Adj) }\end{array}$} & \multirow[b]{2}{*}{$\begin{array}{l}\text { Lines } \\
\text { (Adj) }\end{array}$} & \multirow[b]{2}{*}{$\begin{array}{l}\text { BVRT } \\
\text { CORR }\end{array}$} & \multirow[b]{2}{*}{$\begin{array}{c}B V R T \\
\text { ERROR }\end{array}$} & \multirow[b]{2}{*}{$\begin{array}{l}\text { Depression } \\
\text { Index }\end{array}$} & \multirow[b]{2}{*}{$\begin{array}{l}\text { Aphasia } \\
\text { Index }\end{array}$} \\
\hline & & & & & & & Similarities & Information & Comprehension & $\begin{array}{c}\text { Matrix } \\
\text { Reasoning }\end{array}$ & & & & & & \\
\hline $1711 \mathrm{KK}$ & RSS & $\mathrm{F}$ & 100 & 13 & 38.75 & 10.5 & 7 & 8 & 6 & 7 & 39 & 15 & 7 & 5 & 1 & 0 \\
\hline $2328 \mathrm{JF}$ & RSS & $\mathrm{F}$ & 100 & 18 & 49.5 & 1.5 & 12 & 12 & 13 & 7 & 41 & 27 & 9 & 1 & 1 & 0 \\
\hline $2025 \mathrm{LB}$ & R OFC & $\mathrm{F}$ & 100 & 16 & 47.75 & 4.75 & 11 & 12 & NA & 13 & 50 & NA & 9 & 1 & 0 & 0 \\
\hline 0318VM & bi OFC & M & 100 & 14 & 60 & 24 & 18 & 16 & 19 & 14 & 43 & 30 & 9 & 1 & 0 & 0 \\
\hline 1589RM & bi OFC & M & 100 & 20 & 51 & 18.25 & 15 & 15 & 18 & 11 & 49 & 28 & 7 & 4 & 1 & 0 \\
\hline 1983DR & bi OFC & $\mathrm{F}$ & 100 & 13 & 38 & 5.5 & 12 & 9 & 15 & 10 & 41 & 24 & 8 & 3 & NA & 0 \\
\hline 0297RF & L OFC & M & 100 & 16 & 51.25 & 19.5 & 11 & 13 & 10 & 10 & 49 & 22 & 7 & 5 & 0 & 0 \\
\hline 0468JG & LFO & M & 100 & 16 & 75.5 & 18.5 & 14 & 14 & 9 & 13 & 50 & 30 & 9 & 1 & 0 & 0 \\
\hline 0675ES & L PFC & $\mathrm{F}$ & 100 & 12 & 73.75 & 12.5 & 12 & 12 & 10 & 12 & 48 & 26 & 8 & 4 & NA & 1 \\
\hline 1649RD & L PFC & M & 100 & 16 & 79.75 & 11 & 14 & 14 & NA & NA & 47 & 30 & 6 & 6 & 0 & 0 \\
\hline $1188 \mathrm{NE}$ & L STS & M & 100 & 18 & 42.25 & 13.5 & 15 & 16 & 15 & 12 & 50 & 27 & 10 & 0 & 1 & 2 \\
\hline $1848 \mathrm{ML}$ & LSTS (w.m.) & M & 100 & 12 & 50 & 4 & 7 & 12 & 11 & 13 & 49 & 29 & 9 & 2 & 0 & 1 \\
\hline $2435 \mathrm{RR}$ & L sub-STS & M & 100 & 12 & 57.75 & 1.5 & NA & 12 & NA & 10 & 50 & NA & 8 & 2 & 0 & 2 \\
\hline $1621 \mathrm{LL}$ & L temp/par & $\mathrm{F}$ & 100 & 9 & 68 & 9.25 & 11 & 7 & 10 & 13 & 46 & 21 & 7 & 4 & 0 & 1 \\
\hline 0858JM & bi occipital & M & 100 & 16 & 52.5 & 15 & 11 & 11 & 15 & 11 & NA & NA & 7 & 3 & NA & NA \\
\hline 0999JLK & L occipital & M & 100 & 16 & 46.5 & 6.5 & 13 & 13 & 15 & 8 & 45 & 28 & 9 & 1 & 0 & 0 \\
\hline BD mean $(S D)$ & & $11 \mathrm{~F}, 26 \mathrm{M}$ & & $13.8(2.9)$ & 57.5 (11.9) & $10.5(5.2)$ & $11.3(3.1)$ & $11.5(2.9)$ & $11.4(3.7)$ & $10.8(2.1)$ & $44.5(4.0)$ & $25.4(3.6)$ & $7.4(1.6)$ & $4.1(2.8)$ & & \\
\hline $\begin{array}{l}\text { Matched NC } \\
\text { mean }(S D)\end{array}$ & & $6 \mathrm{~F}, 12 \mathrm{M}$ & & $14.6(2.6)$ & $57.4(13.4)$ & - & $11.7(3.2)$ & $11.7(3.7)$ & $12.2(2.4)$ & $12(3.6)$ & - & - & - & - & - & - \\
\hline Ref NC mean $(S D)$ & & $25 \mathrm{~F}, 16 \mathrm{M}$ & & $15.1(2.4)$ & $47.8(14.3)$ & - & $12.7(2.5)$ & $12.5(3.1)$ & $13.7(2.4)$ & $13.9(2.3)$ & - & - & - & - & - & - \\
\hline
\end{tabular}

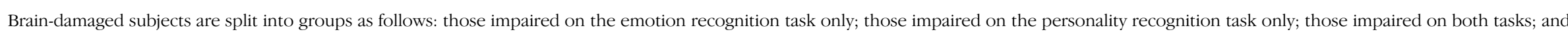

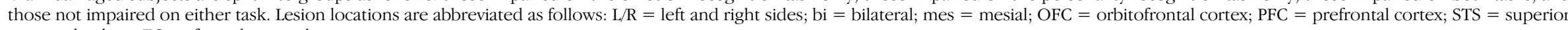
temporal sulcus; $\mathrm{FO}=$ frontal operculum.

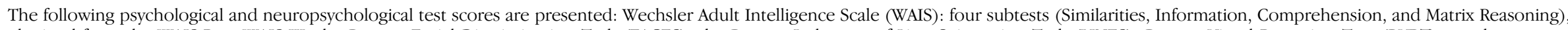

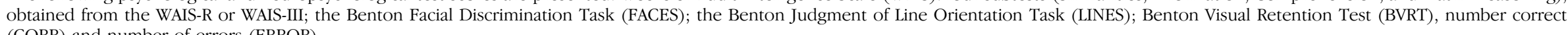
(CORR) and number of errors (ERROR).

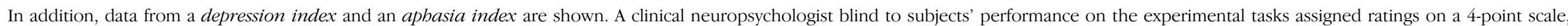

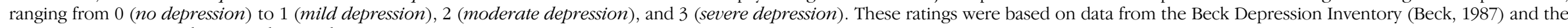
MMPI (or MMPI-2), Scale 2 (Butcher et al., 1989).

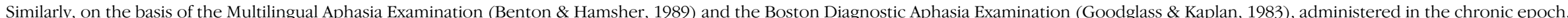

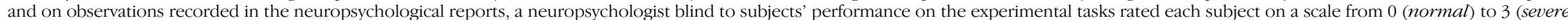
impairment) in terms of speech and language functioning. These scores thus represent summary measures of the overall degree of speech/language impairment in each subject.) 
Figure 3. Lesions that impair recognition of personality traits. Shown are the overlaps of lesions from subjects who were impaired at personality trait recognition from point-light walkers $(>2 S D$ s below NC mean). The greatest overlap was in left opercular regions. Normalization for overall lesion sampling density revealed a similar pattern (not shown).

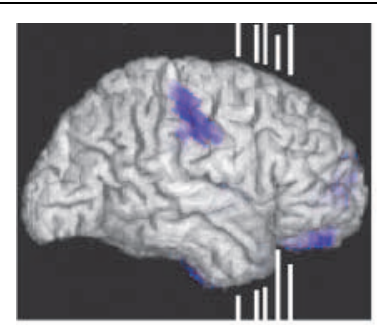

Lesion overlap of 9 subjects, $>2$ S.D. worse than NCs on pointlight personality task
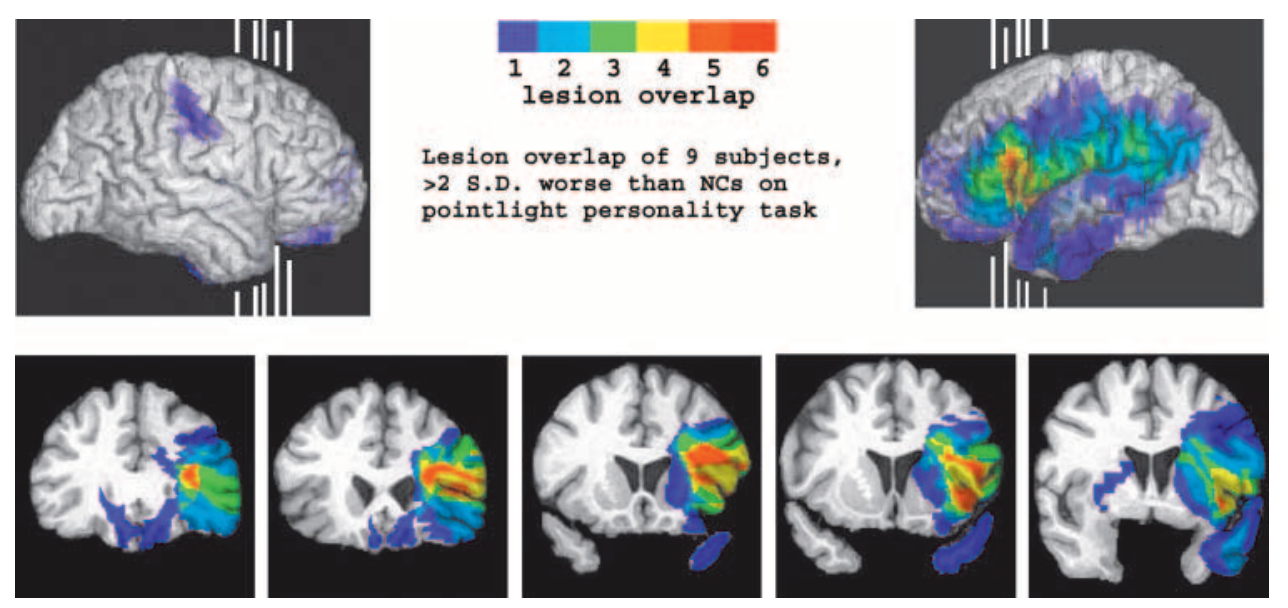

\section{Importance of Right Somatosensory Cortices for Emotion Recognition from Point-Light Walkers}

Because right somatosensory cortices have been implicated in emotion recognition from other types of cues in previous studies (cf. Introduction), we specifically examined the emotion task performance of all 8 subjects whose lesions included the right postcentral gyrus. Five of these 8 subjects scored more than 2 SDs below the NC mean on the emotion recognition task, and 1
Figure 4. Recognition of emotion or personality depends on dissociable neural regions. We selected subjects who performed worse on one task than on the other (see Methods). Top, subjects who were impaired on the emotion task, but less impaired on the personality task. Note overlap in right somatosensory regions. Bottom, subjects who were impaired on the personality task, but less impaired on the emotion task. Note overlap in left premotor regions.

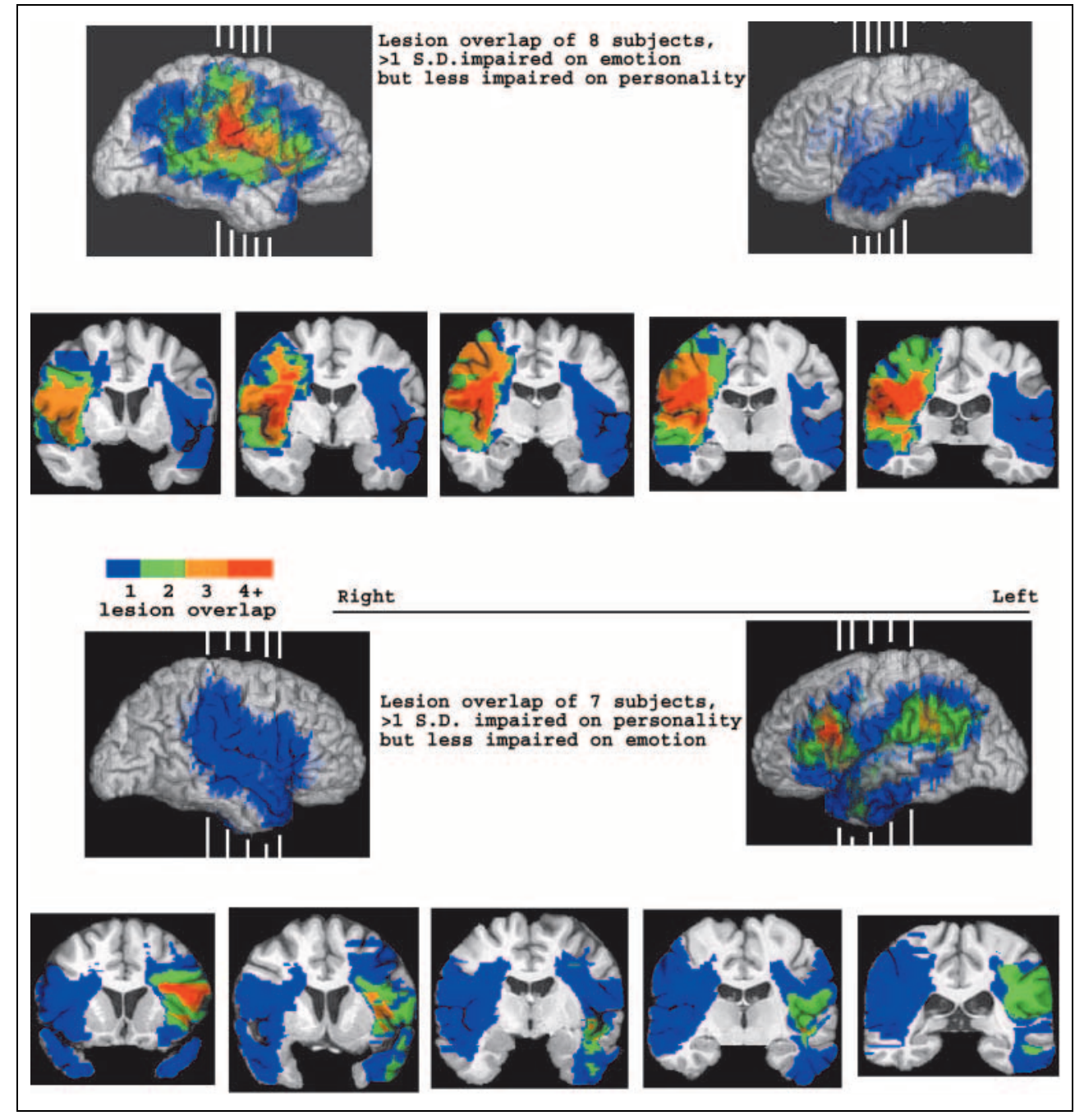


scored between 1 and 2 SDs below the NC mean. The other two subjects with right somatosensory cortex damage scored normally on this task. As a group, these 8 subjects' emotion correctness scores are significantly below those of a group of 18 matched NC subjects (Mann-Whitney $U$ test, $p<.0005$ ).

\section{Importance of Left Frontal Opercular Cortices for Personality Judgments From Point-Light Walkers}

Although we did not predict that damage to the left frontal operculum would result in deficits in personality trait judgments (and not emotion judgments), the lesion overlap analyses described above implicated the left frontal operculum in personality judgments. To follow up this result, we performed a similar analysis comparing all 7 subjects with left frontal opercular damage to the 18 matched NC subjects on the personality task. Of these 7, 5 were more than $2 S D$ s below the NC mean on this task, and one was $1 S D$ below the mean. As a group, these 7 subjects' personality task scores are significantly below that of the 18 matched NC subjects (Mann-Whitney $U$ test, $p<.005$ ).

\section{Relationship of Movement Labeling Control Task to Emotions and Personality Tasks}

To control for deficits in recognition of "nonsocial" (i.e., not emotion or personality) information from pointlight walkers, we examined the relationship of subjects' ability to label the forms of locomotion exhibited by the walkers (walking, running, and so forth) with their ability to judge emotions and personality traits from the same stimuli. Six subjects were impaired ( $>2 S D s$ below the NC mean) at labeling the form of locomotion depicted by point-light walkers, but no clear region of overlap was associated with this deficit. We examined the relationship between performance on this movement labeling task to performance on the two social judgment tasks. Four of the six subjects impaired on the movement task are also 2 SDs below the NC mean on both the emotion and the personality tasks; one is impaired at this level on just the personality task (though is $1 S D$ below the mean on the emotion task), and one is just $1 S D$ below the mean on both tasks.

Conversely, four of the five subjects who were $2 S D$ s below the NC mean on both the emotion task and the personality task were impaired on the movement labeling task as well. However, there were clear deficits on either one of the social judgment tasks individually that occurred in the absence of deficits recognizing the movements: Of the seven subjects who are impaired on the emotion task but not on the personality task, none are impaired on the movement labeling task. Of the four subjects who are impaired on the personality task but not on the movement task, only one is impaired on the movement task. Thus, whereas impaired nonsocial movement recognition invariably resulted in at least mild impairments in emotion and personality judgments, the latter impairments could occur without an impairment in nonsocial movement recognition and labeling. We return to this issue in the Discussion.

\section{Control Measures: Demographic Variables, Neuropsychological Tests, and Visual Perception}

To assess whether differences in age, education level, basic verbal skills/IQ, or basic visuoperceptual functioning underlay the above findings, these data were compared for the groups of brain-damaged subjects who performed best and worst, respectively, on the two social judgment point-light walker tasks. Thus, we compared the 15 subjects with the best emotion judgment scores to the 15 subjects with the worst emotion judgment scores, on several neuropsychological measures (see Methods) via two-sample $t$ tests. The subjects with the worst emotion judgment scores had significantly lower mean scores on two tests of visuoperceptual ability: The Benton Line Orientation task $(p<.05)$ and Benton Visual Retention Task (BVRT; number correct; $p<.005)$; there were no significant differences on any other neuropsychological measures. We also compared these same demographic and neuropsychological measures for the 15 subjects with the best and worst personality judgment scores. These two groups differed significantly on three measures, the verbal IQ subtests $(p<.05)$, the Benton Faces task $(p<.05)$ and the Benton Lines task $(p<.05)$.

To ensure that visuospatial deficits could not fully account for deficits in either the emotion judgment task or the personality judgment task, we performed regression analyses of emotion and personality judgment task scores separately for each of the three visuospatial neuropsychological tests implicated in the above analyses (BVRT, the Benton Lines Task, and the Benton Faces Task). We used the regression results in two ways. First, $r^{2}$ values were fairly low for each of these analyses (emotion task: with BVRT, $r^{2}=.189$; with lines, $r^{2}=.032$; with faces, $r^{2}=.103$; personality task: with BVRT, $r^{2}=.075$; with lines, $r^{2}=.041$; with faces, $\left.r^{2}=.104\right)$. Thus, much of the variance in brain-damaged subjects' task performance was not accounted for by their visuospatial neuropsychological test performance. Second, we compared the residuals from each of these regressions for the 15 worst and 15 best emotion task scorers for whom we had neuropsychological data. We did the same comparisons for the 15 worst and 15 best personality task scorers. In all six of these comparisons, $t$ tests confirmed that the residuals were significantly different for the high versus low scorers on the social judgment tasks (all ps «.01). 


\section{DISCUSSION}

\section{Relationship between Emotion Recognition and Personality Trait Recognition}

Thirteen brain-damaged subjects were impaired at making emotion judgments from point-light walkers, relative to a group of matched normal controls. A partially overlapping group of 9 brain-damaged subjects was impaired at a different social judgment task, judging personality traits, from an overlapping set of point-light stimuli. Not surprisingly, performance on these tasks was weakly correlated; nonspecific deficits after brain damage can lead to overall poorer performance across tasks. What is striking is that deviations from the correlation occurred in both directions: Extending the logic of a two-case double dissociation to group analyses, we found that groups of subjects were impaired on each task in the absence of impairments on the other task. Seven subjects were impaired on the emotion task but not the personality task, and 4 were impaired on the personality task but not the emotion task. A double dissociation does not imply that two processes are always separate, but that they can be separated; thus, the process of judging that a point-light walker is in a certain emotional state is separable from judging that a point-light walker is a certain kind of person, and vice versa.

Impairments in judging emotions from point-light walkers were associated with damage to several components of a network of neural structures, with the most reliable region of lesion overlap associated with this impairment in right somatosensory cortices. This region was a consistent focus of maximal lesion overlap in three overlap analyses: All subjects impaired in emotion judgments; the same overlap normalized for sampling density; and subjects who showed a greater impairment in judging emotion than in judging personality traits. In contrast, impairments in judging personality traits from point-light walkers were associated with damage to the left frontal operculum, which was a consistent focus of maximal lesion overlap in three overlap analyses: all subjects impaired in personality trait judgment, the same overlap normalized for sampling density, and subjects who showed a greater impairment in judging personality than in judging emotion.

These two tasks differ in more than one way, and it is important to be aware of differences between the tasks that may explain at least part of the difference in lesion overlap. One possibility is that the words used in one task are more difficult than those used in the other. However, this explanation could only result in a single dissociation, not the double dissociation we in fact observed. It remains possible that one aspect of our findings, namely, impaired judgment of personality traits following damage to what are classically thought of as language-related regions in the left hemisphere, might be attributable to differences in the difficulty of the words used. Although frequency of word use is only one measure of word "difficulty," a comparison of the incidence of the 5 emotion words and the 10 personality words we used shows that all 5 emotion words occur in the top 5000 most commonly used North American English words, according to the Brown Corpus, an index of word use (lists available at www.edict.com.hk/ lexiconindex/). In contrast, whereas 3 of the personality trait words were also in the top 5000 list, the others are not. Thus, it is possible that subjects who performed poorly on the personality task did so because of difficulties in mapping the personality terms appropriately onto their associated concepts. This possibility is supported by significantly lower scores on a verbal IQ measure for those subjects who performed poorly on the personality task, relative to subjects who performed well. However, it is also worth noting that the aphasia index did not differ between these two groups: Some aphasic individuals performed poorly, but some performed normally, and there were a number of subjects who performed very poorly but were not aphasic (see Table 1). Thus, it does not appear that language differences between the tasks can completely account for the dissociation we observed.

Another difference between the emotion task and the personality task is that the emotion task is a five-alternative forced-choice task, and the personality task is a rating task. Rating each point-light walker stimulus on a scale between, for example, friendly and unfriendly may engage different processes than choosing the most applicable from a list of emotion words. To address this issue, we compared the groups of subjects who were impaired on either of the two social judgment tasks on two measures directly comparable to these tasks in terms of format: a face emotion rating task (Adolphs et al., 2000) and a forced-choice face matching task (Benton, Sivan, Hamsher, Varney, \& Spreen, 1994). In the face emotion rating task, subjects rate each face on Likert scales; on the face matching task, subjects choose from a series of photos one that is of the same individual as a target photo. The group of subjects impaired on the point-light emotion task did not differ on either measure from the group of subjects impaired on the point-light personality task. This finding implies that the task format alone (forced choice in one case, and Likertscale rating in another case) is not sufficient to explain the findings of the current study. However, it will be important in future work to replicate our results with identical formats.

A third difference between the emotion task and the personality task is that, as noted in the Introduction, deciding whether someone's behavior is indicative of a personality trait may rely more heavily on prior knowledge than deciding whether a similar behavior is indicative of an emotional state. If, as many theorists have argued, personality traits are in fact stable over extended periods of time, then it may be harder to judge what 
someone would behave like if one were a certain kind of person; one has experienced only one's own traits from the inside. In contrast, any given person knows what it feels like to experience all of the basic emotions, and thus it may be easier to know what someone would behave like if he/she were in a certain emotional state. This difference suggests that the differential involvement of cortical regions in trait versus state judgments may be due to differences in the extent to which prior knowledge is necessary to make these two types of judgments; further research is necessary to explore this possibility. Similar experiments with face stimuli would provide needed converging evidence.

The neuropsychological comparisons bear further discussion. As noted above, subjects who performed poorly on the personality task scored significantly lower than nonimpaired subjects on a verbal IQ measure, and thus verbal deficits may explain at least part of their impairment on the personality task. These impaired subjects also scored lower on two tests of visuospatial functioning, the Benton Face Matching Task and the Benton Line Orientation Task. Not surprisingly, poor visuospatial function may thus account for poor performance on either the emotion task or the personality task. However, visuospatial perception abilities are not more important for emotion judgments from point-light walkers than for personality judgments from the same stimuli, and thus these findings cannot explain the double dissociation we observed. Furthermore, we found that the residuals from regressions between visuospatial perception tasks and the target social judgment tasks were significantly different for low versus high scorers on the social judgment tasks. This result confirms that the social judgment tasks were tapping something other than basic visuospatial ability: Subjects differed on these tasks in ways not accounted for by their basic visuospatial test scores.

\section{The Relation between Labeling Movements from Point-Light Walkers and Labeling Emotion and Personality from the Same Stimuli: The Role of Simulation}

Our control task deserves a brief further discussion. We chose to use the same point-light stimuli in our control as in our target tasks in an effort to control as well as possible for all the visual properties of the stimuli. The ability to label the form of locomotory movement depicted by a point-light walker includes both a perceptual and a labeling component. This ability appears to be necessary but not sufficient for emotion labeling. All of the subjects who were impaired at labeling the pointlight walkers' movements were at least mildly impaired on both the emotion task and the personality task. However, there were several subjects who were impaired on one or the other social task but not on the movement task. It is also worth noting that of the five subjects who were impaired on both social tasks four were also impaired on the movement task. These results imply that failure to recognize and label the point-light walker's movements may underlie deficits in social judgments, but deficits in social judgments cannot be explained only by failure to adequately recognize the motion stimulus. It should be noted, however, that in those cases where subjects were impaired on the target task(s) as well as the control task, we cannot distinguish between at least two different possibilities: (1) They are impaired because they fail to perceive the stimulus normally or (2) they are impaired because of a broader, nonperceptual impairment that encompasses our experimental task as well as such tasks as action naming and verb generation (required in our control task). Possibility (2) bears further explanation, as there is some evidence that one of the regions found critical for personality trait recognition in our present study (the left frontal operculum) is important also in action naming and verb-generation tasks (Tranel, Kemmerer, Damasio, Adolphs, \& Damasio, 2003; Cappa, Sandrini, Rossini, Sosta, \& Miniussi, 2002; Damasio et al., 2001; Tranel, Adolphs, Damasio, \& Damasio, 2001; Herholz et al., 1996; Daniele, Giustolisi, Silveri, Colosimo, \& Gainotti, 1994; Damasio \& Tranel, 1993). When we examined the lesion overlap of subjects who showed impairment on the control task of labeling point-light walkers' movements, we did not find a corresponding area of maximal lesion overlap. Although we might expect a region of overlap in the left frontal opercular cortices based on the above studies, our control task was not designed to address this issue. Rather, its purpose was to rule out deficits in social judgment tasks that are due to less specific deficits in recognizing locomotory movements from point-light walker stimuli. Our failure to find an overlap in subjects who were impaired at labeling locomotory movement patterns in point-light walkers indicates that possibility (1) above is more likely: These subjects are impaired on both the control task and at assigning social meaning to the locomotory patterns due to nonspecific perceptual impairments and not to a single underlying process. This confirms the validity of using the movement-labeling task as a control task.

The co-occurrence of impairments in recognizing forms of locomotory movement and recognizing emotions from these movements dovetails nicely with the simulation theory of emotion recognition. Deficits in modeling another person's movements in one's own premotor cortex, somatosensory cortex, or both might lead to impairments in both tasks. However, it is conceivable that someone could recognize movements normally but still not be able to model what it "feels like" to move in a given way. Thus, internal simulation of movements may be a necessary but not sufficient component of a more complete simulation of movement with emotional state markers. Several researchers 
have postulated that simulation processes underlie our ability to infer intentions from movement, including from point-light walkers (see Blakemore \& Decety, 2001; Gallese \& Goldman, 1998). In simulation theories, "mirror neurons" in the frontal operculum, possibly primarily on the left, are thought to be engaged in creating a representation of actions whether observed or performed by the subject. Frontal opercular cortices have been shown to be active when subjects judged emotional facial expressions (Kesler-West et al., 2001). Furthermore, as noted above, Adolphs et al. (2000, 2002) have found deficits in emotion recognition from faces and from prosody after damage to either the frontal operculum or right somatosensory cortices. Somatosensory cortices may function in simulation processes of emotion recognition by creating a representation of the feeling associated with a given emotional behavior (Adolphs, 2002). Interestingly, Winston et al. (2003) showed that right somatosensory cortices are engaged during an emotion recognition task, but not during "incidental" emotion processing when the same faces are viewed as part of a gender recognition task. In summary, when explicitly attributing emotional states based on observations of behavior (visual or auditory), we may use internal models of the movements that correspond with the observed behavior to generate a representation of what it would feel like to look (or sound) like the person we observe.

Given the above model of emotion recognition via simulation, it is not surprising that right somatosensory cortices and the left frontal operculum both play roles in recognizing social information from point-light walkers. However, it is more difficult to explain the particular dissociation that we observed. People may use simulation processes differently when inferring that a person moving in a certain way feels a given emotion (a state judgment) as compared to drawing inferences from the same information about a person's general pattern of behavior (a trait judgment). This possibility is fascinating, and further work is necessary to address (1) whether the same dissociation is found when subjects are making similar judgments from other types of cues (e.g., faces, verbal descriptions of behavior) and (2) whether the anatomical areas shown here to be relevant for emotion and personality trait judgments from point-light walkers will also turn out to be engaged in functional imaging studies in which these tasks are performed by neurologically normal subjects.

\section{METHODS}

\section{Subjects}

\section{Normal Controls}

We tested 62 neurologically normal controls between the ages of 29 and 87 . Of these, three were excluded from all analyses due to one of the following exclusionary criteria: significant vision problems (1), experimenter error (1), being an outlier on all tasks (1). The 59 remaining normal controls were divided into two subgroups as follows. The comparison group, or matched NC group, consisted of 18 subjects (6 women, 12 men) matched to the target subjects with respect to age, gender ratio, and approximate educational level (see Table 1 for demographic and IQ information). The remaining 41 subjects comprised the reference $N C$ group, whose ratings of stimuli were used solely as a reference to assign "correctness" scores (see Table 1 for demographic and IQ information).

\section{Brain-damaged Subjects}

We tested 37 subjects with adult-acquired damage that included cortical regions. All subjects' lesions were due to stroke or to surgery, and none had a history of epilepsy. The extent of subjects' lesions was variable, and included cortices (and underlying white matter) in the frontal, temporal, parietal, and, to a lesser extent, occipital lobes. Subjects' lesions had been mapped onto a common reference brain, allowing visualization of the extent of lesion overlap (Figure 2).

All brain-damaged participants were selected from the Patient Registry of the Division of Cognitive Neuroscience, Department of Neurology, University of Iowa, and had been fully characterized neuropsychologically (Tranel, 1996) and neuroanatomically (Damasio, 2000; Frank, Damasio, \& Grabowski, 1997). Our exclusion criterion was impairment in basic visual perception, attention, or any other abilities that was sufficiently severe that they would affect subjects' ability to give a valid performance on the target tasks, as judged by a clinical neuropsychologist who had been shown the tasks but had no other knowledge of the study hypotheses. All subjects were thought to be able to give valid performance except one who, due to aphasia, was thought to be potentially impaired, but equally for both tasks. All participants also conformed to the inclusion criteria of the Patient Registry: They had focal, chronic, stable, adult-acquired lesions that could be clearly identified on MR or CT scans. Note that this excluded the following: Subjects with metal clips whose lesions could not be clearly delineated due to imaging artifacts (i.e., many subjects with damage due to surgeries), subjects with lesions acquired developmentally, and subjects with encephalitis that resulted in lesions with unclear boundaries. All participants had IQs in the normal range, and none were demented. The subjects were studied in the chronic epoch, that is, more than 3 months after lesion onset (see Table 1 for demographic and neuropsychological information for all brain-damaged subjects). All subjects gave informed consent, as approved by the University of Iowa Institutional Review Board. 


\section{Stimuli and Tasks}

\section{Construction of Point-Light Stimuli}

Twelve small lights were attached to the major joints and the head of a male actor. He was filmed portraying specific emotions and personality traits while moving in a dark room. We did not take into account the actor's intention in determining what emotion category or personality trait was "correct" for a given stimulus. All correctness scores were based on the answers given by the reference group of normal controls (see below). Pilot testing enabled us to eliminate the stimuli that elicited the most variable judgments, yielding sets of 33 simple emotion movies and 41 personality trait movies. These sets overlapped: 29 movies were common to both sets, with 4 additional movies in the emotion set and 12 in the personality set. We constructed an additional set of 9 movies chosen from the sets of emotion and personality movies for use in a control task in which subjects identified various types of movement (e.g., walking, creeping, and marching). Stimuli were presented in a fixed random order and varied in length from 3 to $55 \mathrm{sec}$ [emotion set: mean 8.5 (SD 6.2); personality set: 8.9 (6.0); movement set: 8.7 (6.7)]. (Examples can be viewed at www.medicine.uiowa.edu/adolphs.)

Stimuli were presented on a Macintosh G-3 Powerbook, with subjects seated approximately $60 \mathrm{~cm}$ from the display. Subjects responded verbally or by pointing to items on the response sheet in front of them. Reaction time was not measured, and subjects were not pressed to respond quickly.

\section{Emotion Judgment}

For the emotion stimulus set, subjects were instructed to pick the word that best described the movement from a list of five words (happy, sad, angry, afraid, and neutral). These emotions were chosen from the set of "basic emotions" (Ekman \& Friesen, 1971); "disgust" and "surprise" were excluded from the stimulus set because it was felt that these emotions could not be clearly conveyed with body movement. The list of emotion words was visible in front of the subject for the duration of testing.

\section{Personality Trait Judgment}

For the personality trait stimulus set, subjects rated each stimulus on five 5-point Likert scales, each of which was anchored by a pair of antonyms defining a personality factor (Extraversion: "Outgoing" and "Shy"; Warmth: "Friendly" and "Unfriendly"; Reliability: "Trustworthy" and "Not trustworthy"; Neuroticism: "Calm" and "Anxious"; Novelty preference: "Stay-at-home" and "Adventurous"; McCrae \& Costa, 1987). ${ }^{1}$ Before each subject began rating stimuli, the experimenter made sure the subject understood (1) the use of the Likert scales, (2) that there is no necessary relationship between any two of the scales (i.e., one could imagine somebody who was outgoing but unfriendly, etc.), and (3) the definitions of each anchor word. As with the emotional state words, the Likert scales were available in front of the subject for the duration of testing.

\section{Movement Description Control Task}

This task was designed to control for more basic impairments in recognizing point-light walkers as human movement stimuli. Subjects were asked to spontaneously generate a verb that described the movement shown in each of nine stimuli, given "walking" as an example. Note that the subject was not told that the stimuli were people, and no further cues regarding the nature of the stimuli were given at any point in the testing process.

All subjects completed all three point-light walker tasks, except one subject who was judged to give an invalid performance on the personality task. This judgment was made by the experimenter at the time of testing, and these data were not entered or analyzed for this subject.

\section{Background Neuropsychological Measures}

Subjects with brain damage were given background neuropsychological and psychological tests to assess intellectual ability, memory, visual perception, depression, and aphasia. Neurologically normal subjects were given tests to assess intellectual ability to facilitate matching with the brain-damaged subjects (Table 1). Thus, all subjects were administered four subtests (Similarities, Information, Comprehension, and Matrix Reasoning) from the Wechsler Adult Intelligence Scale (WAIS-R or WAIS-III; Wechsler, 1991). Subjects with brain damage were also given the Benton Facial Discrimination Task (Benton et al., 1994), the Benton Judgment of Line Orientation Task (Benton et al., 1994); and the Benton Visual Retention Test (Benton Sivan, 1992) to assess basic visuoperceptual abilities. To assess depression, a clinical neuropsychologist blind to subjects' performance on the experimental tasks assigned ratings on a 4-point scale, ranging from 0 (no depression), 1 (mild depression), 2 (moderate depression), to 3 (severe depression). These ratings were based on data from the Beck Depression Inventory (Beck, 1987) and the Minnesota Multiphasic Personality Inventory (MMPI or MMPI-2), Scale 2 (Butcher, Dahlstrom, \& Graham, 1989). Similarly, on the basis of the Multilingual Aphasia Examination (Benton \& Hamsher, 1989), the Boston Diagnostic Aphasia Examination (Goodglass \& Kaplan, 1983), and on observations recorded in the neuropsychological reports, a neuropsychologist blind to subjects' performance on the experimental tasks rated each subject on a scale from 
0 (normal) to 3 (severe impairment) in terms of speech and language functioning. Scores thus represent summary measures of the overall degree of speech/language impairment in each subject. The neuropsychological tests of memory and visual perception were administered only to the brain-damaged subjects because the normal controls were presumed to be normal in these functions. Similarly, the depression and aphasia indices were obtained in brain-damaged subjects but not in normal controls.

\section{Data Processing and Analysis}

\section{Emotion Judgment}

Emotion labels attributed by subjects with brain damage were compared to those given by the NC reference group in the following way: Each response was given credit based on the proportion of subjects in the reference group giving that response. For example, if a given stimulus was called "happy" by $50 \%$ of the reference group, "angry" by 40\%, and "neutral" by 10\%, then the response "happy" would receive a score of $1.0(.5 / .5)$, "angry" would receive .8 (.4/.5), and "neutral" would receive .2 (.1/.5). All other answers (in this example, "sad" and "afraid") would receive 0 . This method accepted as normal a certain degree of variability in the reference group responses. It is easy to imagine that a stimulus can be recognized as both afraid and sad, for example, and therefore a response that was not the modal response could still be given partial credit.

For the correctness scores derived from the reference NC group answers, higher numbers imply answers that were chosen a large number of times by the NC reference group. We examined average correctness scores across all stimuli and correctness scores for groups of stimuli with the same modal response. We used the entire NC group's modal response to determine which category a given stimulus was a member of (i.e., if the majority of subjects in the entire NC group called a movie "happy," then it was considered a happy movie).

Table 2. Number of Stimuli Included in Each Emotion Category, as Well as Mean Correctness Scores for the Matched NC Group for Each Category

\begin{tabular}{lcc}
\hline $\begin{array}{c}\text { Judgment } \\
\text { Category }\end{array}$ & $\begin{array}{c}\text { Number of } \\
\text { Stimuli }\end{array}$ & $\begin{array}{c}\text { Matched NC } \\
\text { Group Mean (SD) }\end{array}$ \\
\hline Happy & 11 & $.776(.15)$ \\
Sad & 7 & $.795(.16)$ \\
Afraid & 5 & $.725(.14)$ \\
Angry & 4 & $.571(.23)$ \\
Neutral & 6 & $.811(.13)$ \\
Emotion mean & 33 & $.754(.05)$ \\
\hline
\end{tabular}

Thus, we examined both performance on emotion recognition in general, and performance on the recognition of individual emotions. See Table 2 for numbers of stimuli in each emotion category and average NC correctness ratings for these stimuli.

\section{Personality Trait Judgment}

Correctness scores were assigned to the personality responses given by brain-damaged subjects and matched NC subjects by taking the absolute value of the $z$ score relative to the reference group. This yields a measure of distance away from the mean rating given by the reference group that is irrespective of direction of difference (e.g., $z$ scores of -2.5 and +2.5 are both 2.5 away from the mean). Because the difference scores obtained by this method are smaller for answers that were closer to the NC mean, we inverted them by subtracting from 2, yielding correctness scores in which larger scores are reflective of answers more like normal control answers. This inversion facilitates a comparison with the emotion correctness score (in which higher scores imply a large number of normal answers); however, in contrast to that score, answers of 1 are not indicative of ceiling performance.

As stated above, all 41 stimuli were rated on all five traits. However, pilot testing revealed that these stimuli frequently failed to elicit reliable responses concerning one or more traits; that is, they did not contain the same amount of useful information about each trait. For example, a slowly creeping point-light walker might be reliably rated as untrustworthy but yield a wide range of responses on the anxiety scale. Therefore, we examined the variance in the responses given by the reference group of normal subjects, and stimuli for which the $S D$ in responses for a given trait was greater than 1.0 were

Table 3. Number of Stimuli Included in Each Personality Trait Category, as Well as Mean Correctness Scores for the Matched NC Group for Each Category

\begin{tabular}{lcc}
\hline $\begin{array}{c}\text { Judgment } \\
\text { Category }\end{array}$ & $\begin{array}{c}\text { Number of } \\
\text { Stimuli }\end{array}$ & $\begin{array}{c}\text { Matched NC Group } \\
\text { Mean (SD) }\end{array}$ \\
\hline Outgoing/shy & 36 & $1.11(.15)$ \\
Friendly/unfriendly & 32 & $1.05(.19)$ \\
$\begin{array}{c}\text { Trustworthy/not } \\
\text { trustworthy }\end{array}$ & 41 & $1.10(.29)$ \\
$\begin{array}{l}\text { Calm/anxious } \\
\text { Stay-at-home/ } \\
\text { adventurous }\end{array}$ & 18 & $1.00(.24)$ \\
Personality mean & (Weighted average) & $1.09(.16)$ \\
\hline
\end{tabular}

Note. The weighted average, which is used as the personality task score, takes into account the number of stimuli included for each category. 
eliminated for further analyses on that trait only (see Table 3 for numbers of stimuli included in each trait analysis and average difference scores for the matched NC group on these stimuli).

\section{Movement Labeling Task}

Subjects' descriptions of the locomotion of point-light walkers (e.g., "walking," "dancing," "strolling," "sauntering") were evaluated by four neurologically normal adult coders who were blind to the identity of the subjects. For each stimulus, the coders judged whether a given answer was a good, mediocre, or inadequate/ incorrect description of the movement (e.g., walking and strolling might both be good descriptions of a walking point-light stimulus, strutting a mediocre description of the same stimulus, and skipping entirely incorrect). These ratings were used to score each answer, such that ratings of "good" scored 1 point, ratings of "mediocre" scored .5 points, and incorrect descriptions scored 0 points. The means of all four raters' scores for each stimulus were then averaged across all stimuli, yielding a correctness measure that reflected how well subjects were able to recognize and label basic locomotory patterns from point-light stimuli. For this task, as for the two others, higher scores reflected better answers.

\section{Lesion Overlap Analysis}

All lesion images were obtained by using the method known as MAP-3 (Damasio, 2000), in which lesions from individual subjects' brains are manually transferred, slice by slice, onto a common, normal, reference brain, creating a "lesion volume." These volumes are then corendered with the reference brain, allowing the visualization of the number of overlapping lesions at each voxel. Lesion location for each individual subject was determined by inspection of 3-D reconstructed MRI data.

We examined the lesion overlap of subjects who were impaired on both the emotion and personality trait judgment tasks (i.e., those who scored 2 SDs below the matched NC mean). In addition, because we did not "sample" the brain uniformly (e.g., we have data from few subjects with occipital lobe damage), we constructed normalized versions of these overlap images. These normalized images were constructed by dividing the lesion overlap of impaired subjects by the lesion overlap of all 37 subjects, yielding images with warmer colors representing areas in which a higher proportion of subjects tested were impaired on a given task. Note that we examined the overlap of impaired subjects only for pixels where at least three subjects overlapped. Without this stipulation, regions in which only one or two subjects had a lesion would have appeared red if either subject was impaired, indicating a high proportion of subjects with damage in these areas were im- paired on the task. Obviously, this would be misleading if only one subject sampled had damage in a given region. Because we observed the same regions of maximal overlap from the normalized pictures as from the nonnormalized versions, we do not show the overlap images for the normalization analysis.

A final overlap analysis examined whether the same regions that were regions of maximal overlap across all impaired subjects were also implicated in subjects who were more impaired on one social task than the other. To examine this, we selected the subset of brain-damaged subjects more impaired on the emotion task than on the personality task, and vice versa. Because an impairment threshold of 2 SDs below the NC mean would have yielded too few subjects for an informative overlap image, we broadened our criterion for this analysis only. Thus, for the overlap image of subjects more impaired on the emotion task than on the personality task, we included those subjects who were 2 SDs below the NC mean for the emotion task but $<2 S D$ s below for the personality task, as well as those $1 S D$ below the $\mathrm{NC}$ mean for the emotion task but $<1 S D$ below for the personality task. The overlap image of subjects more impaired on the personality task than on the emotion task was constructed similarly.

\section{Acknowledgments}

Supported by NINDS Program Project Grant NS19632. ASH was supported by NIH T32-NS07413 at the Children's Hospital of Philadelphia during preparation of the final manuscript. We are grateful to Josh Greene, Lavanya Vijayaraghavan, and two anonymous reviewers for comments on earlier versions of this manuscript, to Sepideh Ravahi, Melissa McGivern, and Matt Karafin for help with testing subjects, to Denise Krutzfeld and Ruth Henson for help in scheduling their visits, and to the people who kindly volunteered to participate in our study.

Reprint requests should be sent to Andrea Heberlein, Center for Cognitive Neuroscience, Department of Psychology, University of Pennsylvania, 3720 Walnut St., Philadelphia, PA 19104, USA, or via e-mail: heberlei@psych.upenn.edu.

\section{Notes}

1. There are many theories about which trait dimensions adequately describe personality variables. We chose the scales here, adapted from McCrae and Costa's "big five," in part because the number was similar to the number of basic emotions we included, and in part because these trait dimensions could be captured by using adjectives that are easily understood by most of the individuals in our subject pools.

\section{REFERENCES}

Adolphs, R. (2002). Recognizing emotion from facial expressions: Psychological and neurological mechanisms. Behavioral and Cognitive Neuroscience Reviews, 1, 21-61.

Adolphs, R., Damasio, H., \& Tranel, D. (2002). Neural systems for recognition of emotional prosody: A 3-D lesion study. Emotion, 2, 23-51. 
Adolphs, R., Damasio, H., Tranel, D., Cooper, G., \& Damasio, A. R. (2000). A role for somatosensory cortices in the visual recognition of emotion as revealed by three-dimensional lesion mapping. The Journal of Neuroscience, 20, 2683-2690.

Adolphs, R., Tranel, D., \& Damasio, A. R. (1998). The human amygdala in social judgment. Nature, 393, 470-474.

Adolphs, R., Tranel, D., Damasio, H., \& Damasio, A. R. (1995). Fear and the human amygdala. The Journal of Neuroscience, 15, 5879-5891.

Adolphs, R., Tranel, D., Hamann, S., Young, A. W., Calder, A. J., Phelps, E. A., Anderson, A., Lee, G. P., \& Damasio, A. R. (1999). Recognition of facial emotion in nine individuals with bilateral amygdala damage. Neuropsychologia, 37, $1111-1117$

Allison, T., Puce, A., \& McCarthy, G. (2000). Social perception from visual cues: Role of the STS region. Trends in Cognitive Sciences, 4, 267-278.

Ambady, N., \& Rosenthal, R. (1992). Thin slices of expressive behavior as predictors of interpersonal consequences: A meta-analysis. Psychological Bulletin, 111, 256-274.

Beck, A. T. (1987). Beck Depression Inventory. San Antonio, TX: The Psychological Corporation.

Benowitz, L. I., Bear, D. M., Rosenthal, R., Mesulam, M. M., Zaidel, E., \& Sperry, R. W. (1983). Hemispheric specialization in nonverbal communication. Cortex, 19, 5-11.

Benton, A. L., \& Hamsher, K. (1989). Multilingual aphasia examination. Iowa City, IA: AJA Associates.

Benton, A. L., Sivan, A. B., Hamsher, K. S., Varney, N. S., \& Spreen, O. (1994). Contributions to neuropsychological assessment. A clinical manual. New York: Oxford.

Benton Sivan, A. (1992). Benton Visual Retention Test (5th ed.). New York: The Psychological Corporation, Harcourt Brace Jovanovich, Inc.

Blakemore, S.-J., \& Decety, J. (2001). From the perception of action to the understanding of intention. Nature Reviews Neuroscience, 2, 561-567.

Bonda, E., Petrides, M., Ostry, D., \& Evans, A. (1996). Specific involvement of human parietal systems and the amygdala in the perception of biological motion. The Journal of Neuroscience, 16, 3737-3744.

Borod, J. C., Obler, L. K., Erhan, H. M., Grunwald, I. S., Cicero, B. A., Welkowitz, J., Santschi, C., \& Agosti, R. M. (1998). Right hemisphere emotional perception: Evidence across multiple channels. Neuropsychology, 12, 446-458.

Bowers, D., Bauer, R. M., Coslett, H. B., \& Heilman, K. M. (1985). Processing of faces by patients with unilateral hemisphere lesions: I. Dissociation between judgments of facial affect and facial identity. Brain and Cognition, 4, 258-272.

Breiter, H. C., Etcoff, N. L., Whalen, P. J., Kennedy, W. A., Rauch, S. L., Buckner, R. L., Strauss, M. M., Hyman, S. E., \& Rosen, B. R. (1996). Response and habituation of the human amygdala during visual processing of facial expression. Neuron, 17, 875-887.

Butcher, J. N., Dahlstrom, W. G., \& Graham, J. R. (1989). Manual for the restandardized Minnesota Multiphasic Personality Inventory: MMPI-2. Minneapolis: University of Minnesota Press.

Calder, A. J., Keane, J., Manes, F., Antoun, N., \& Young, A. W. (2000). Impaired recognition and experience of disgust following brain injury. Nature Neuroscience, 3, 1077-1078.

Calder, A. J., Young, A. W., Perrett, D. I., Hodges, J. R., \& Etcoff, N. L. (1996). Facial emotion recognition after bilateral amygdala damage: Differentially severe impairment of fear. Cognitive Neuropsychology, 13, 699-745.

Cappa, S. F., Sandrini, M., Rossini, P. M., Sosta, K., \& Miniussi,
C. (2002). The role of the left frontal lobe in action naming: rTMS evidence. Neurology, 59, 720-723.

Cutting, J. E., \& Kozlowski, L. T. (1977). Recognizing friends by their walk: Gait perception without familiarity cues. Bulletin of the Psychonomic Society, 9, 353-356.

Damasio, A. R., \& Tranel, D. (1993). Nouns and verbs are retrieved with differently distributed neural systems. Proceedings of the National Academy of Sciences, U.S.A., 90, 4957-4960.

Damasio, H. (2000). The lesion method in cognitive neuroscience. In F. B. J. Grafman (Ed.), Handbook of neuropsychology, 2nd edition (Vol. 1, pp. 77-102). New York: Elsevier.

Damasio, H., Grabowski, T. J., Tranel, D., Ponto, L. L., Hichwa, R. D., \& Damasio, A. R. (2001). Neural correlates of naming actions and of naming spatial relations. Neuroimage, 13, 1053-1064.

Daniele, A., Giustolisi, L., Silveri, M. C., Colosimo, C., \& Gainotti, G. (1994). Evidence for a possible neuroanatomical basis for lexical processing of nouns and verbs.

Neuropsychologia, 32, 1325-1341.

Dittrich, W. H., Troscianko, T., Lea, S. E., \& Morgan, D. (1996). Perception of emotion from dynamic point-light displays represented in dance. Perception, 25, 727-738.

Dolan, R. J., Fletcher, P. C., Morris, J. S., Kapur, N., Deakin, J. F. W., \& Frith, C. D. (1996). Neural activation during covert processing of positive emotional facial expressions. Neuroimage, 4, 194-200.

Ekman, P., \& Friesen, W. V. (1971). Constants across cultures in the face and emotion. Journal of Personality and Social Psychology, 17.

Fiske, S. T. (1993). Social cognition and social perception. Annual Reviews in Psychology, 44, 155-194.

Frank, R. J., Damasio, H., \& Grabowski, T. J. (1997). Brainvox: An interactive, multimodal visualization and analysis system for neuroanatomical imaging. Neuroimage, 5, 13-30.

Gallese, V., \& Goldman, A. (1998). Mirror neurons and the simulation theory of mind-reading. Trends in Cognitive Sciences, 2, 493-501.

Gilbert, D. T. (1998). Ordinary personology. In D. T. Gilbert, S. T. Fiske, \& G. Lindzey (Eds.), The handbook of social psychology (4th ed., pp. 89-150). New York: McGraw Hill.

Goodglass, H., \& Kaplan, E. (1983). Boston Diagnostic Aphasia Examination. Philadelphia: Lea and Febiger.

Greenwald, A. G., \& Banaji, M. R. (1995). Implicit social cognition: Attitudes, self-esteem, and stereotypes. Psychological Review, 102, 4-27.

Grezes, J., Fonlupt, P., Bertenthal, B., Delon-Martin, C., Segebarth, C., \& Decety, J. (2001). Does perception of biological motion rely on specific brain regions? Neuroimage, 13, 775-785.

Grossman, E., Donnelly, M., Price, R., Pickens, D., Morgan, V., Neighbor, G., \& Blake, R. (2000). Brain areas involved in perception of biological motion. Journal of Cognitive Neuroscience, 12, 711-720.

Grossman, E. D., \& Blake, R. (2002). Brain areas active during visual perception of biological motion. Neuron, $35,1167-1175$.

Gunns, R. E., Johnston, L., \& Hudson, S. M. (2002). Victim selection and kinematics: A point-light investigation of vulnerability to attack. Journal of Nonverbal Behavior, 26, 129-158.

Hart, A. J., Whalen, P. J., Shin, L. M., McInerney, S. C., Fischer, H., \& Rauch, S. L. (2000). Differential response in the human amygdala to racial outgroup vs. ingroup face stimuli. NeuroReport, 11, 2351-2355. 
Herholz, K., Thiel, A., Wienhard, K., Pietrzyk, U., von Stockhausen, H. M., Karbe, H., Kessler, J., Bruckbauer, T., Halber, M., \& Heiss, W. D. (1996). Individual functional anatomy of verb generation. Neuroimage, 3, 185-194.

Hornak, J., Rolls, E. T., \& Wade, D. (1996). Face and voice expression identification in patients with emotional and behavioural changes following ventral frontal lobe damage. Neuropsychologia, 34, 247-261.

Johansson, G. (1973). Visual perception of biological motion and a model of its analysis. Perception and Psychophysics, 14, 202-211.

Kawasaki, H., Adolphs, R., Kaufman, O., Damasio, H., Damasio, A. R., Granner, M., Bakken, H., Hori, T., \& Howard, M. A. (2001). Single-unit responses to emotional visual stimuli recorded in human ventral prefrontal cortex. Nature Neuroscience, 4, 15-16.

Kesler-West, M. L., Andersen, A. H., Smith, C. D., Avison, M. J., Davis, C. E., Kryscio, R. J., \& Blonder, L. X. (2001). Neural substrates of facial emotion processing using fMRI. Brain Research, Cognitive Brain Research, 11, 213-226.

Kozlowski, L. T., \& Cutting, J. E. (1977). Recognizing the sex of a walker from a dynamic point-light display. Perception and Psychophysics, 21, 575-580.

Macrae, C. N., \& Bodenhausen, G. V. (2000). Social cognition: Thinking categorically about others. Annual Reviews in Psychology, 51, 93-120.

Makeig, P. (2001). Sensitivity to kinematic specification of emotion and emotion-related states. Unpublished master's thesis, Canterbury University, New Zealand.

Marinkovic, K., Trebon, P., Chauvel, P., \& Halgren, E. (2000). Localized face processing by the human prefrontal cortex: Face-selective intracerebral potentials and post-lesion deficits. Cognitive Neuropsychology, 17, 187-199.

McCrae, R. R., \& Costa, P. T. Jr. (1987). Validation of the five-factor model of personality across instruments and observers. Journal of Personality and Social Psychology, 52, 81-90.

Milne, E., \& Grafman, J. (2001). Ventromedial prefrontal cortex lesions in humans eliminate implicit gender stereotyping. The Journal of Neuroscience, 21, RC150.

Mischel, W., \& Shoda, Y. (1995). A cognitive-affective system theory of personality: Reconceptualizing situations, dispositions, dynamics, and invariance in personality structure. Psychological Review, 102, 246-268.

Morris, J. S., Frith, C. D., Perrett, D. I., Rowland, D., Young, A. W., Calder, A. J., \& Dolan, R. J. (1996). A differential neural response in the human amygdala to fearful and happy facial expressions. Nature, 383, 812-815.

Phelps, E. A., O'Connor, K. J., Cunningham, W. A., Funayama, E. S., Gatenby, J. C., Gore, J. C., \& Banaji, M. R. (2000). Performance on indirect measures of race evaluation predicts amygdala activation. Journal of Cognitive Neuroscience, 12, 729-738.

Phillips, M. L., Young, A. W., Scott, S. K., Calder, A. J., Andrew, C., Giampietro, V., Williams, S. C. R., Bullmore, E. T.,
Brammer, M., \& Gray, J. A. (1998). Neural responses to facial and vocal expressions of fear and disgust. Proceedings of the Royal Society of London B, 265, 1809-1817.

Pollick, F. E., Paterson, H. M., Bruderlin, A., \& Sanford, A. J. (2001). Perceiving affect from arm movement. Cognition, 82, B51-B61.

Servos, P., Osu, R., Santi, A., \& Kawato, M. (2002). The neural substrates of biological motion perception: An fMRI Study. Cerebral Cortex, 12, 772-782.

Sprengelmeyer, R., Rausch, M., Eysel, U. T., \& Przuntek, H. (1998). Neural structures associated with recognition of facial expressions of basic emotions. Proceedings of the Royal Society of London B, 265, 1927-1931.

Sprengelmeyer, R., Young, A., Schroeder, U., Grossenbacher, P. G., Federlein, J., Buettner, T., \& Przuntek, H. (1999). Knowing no fear. Proceedings of the Royal Society of London B, 266, 2451-2456.

Tranel, D. (1996). The Iowa-Benton school of neuropsychological assessment. In I. Grant \& K. M. Adams (Eds.). Neuropsychological assessment of neuropsychiatric disorders (pp. 81-101). New York: Oxford University Press.

Tranel, D., Adolphs, R., Damasio, H., \& Damasio, A. R. (2001). A neural basis for the retrieval of words for actions. Cognitive Neuropsychology, 18, 655-674.

Tranel, D., Kemmerer, D., Damasio, H., Adolphs, R., \& Damasio, A. R. (2003). Neural correlates of conceptual knowledge for actions. Cognitive Neuropsychology, 20, 409-432.

Vaina, L. M., Solomon, J., Chowdhury, S., Sinha, P., \& Belliveau, J. W. (2001). Functional neuroanatomy of biological motion perception in humans. Proceedings of the National Academy of Sciences, U.S.A, 98, 11656-11661.

Vuilleumier, P., Armony, J. L., Driver, J., \& Dolan, R. J. (2001). Effects of attention and emotion on face processing in the human brain: An event-related fMRI study. Neuron, 30, 829-841.

Wechsler, D. (1991). Wechsler Adult Intelligence Scale-III. New York: The Psychological Corporation.

Whalen, P. J., Rauch, S. L., Etcoff, N. L., McInerney, S. C., Lee, M. B., \& Jenike, M. A. (1998). Masked presentations of emotional facial expressions modulate amygdala activity without explicit knowledge. The Journal of Neuroscience, 18, 411-418.

Winston, J. S., O'Doherty, J., \& Dolan, R. J. (2003). Common and distinct neural responses during direct and incidental processing of multiple facial emotions. Neuroimage, 20, 84-97.

Winston, J. S., Strange, B. A., O’Doherty, J., \& Dolan, R. J. (2002). Automatic and intentional brain responses during evaluation of trustworthiness of faces. Nature Neuroscience, 5, 277-283

Young, A. W., Aggleton, J. P., Hellawell, D. J., Johnson, M., Broks, P., \& Hanley, J. R. (1995). Face processing impairments after amygdalotomy. Brain, 118, 15-24. 